Article

\title{
Where's Wally? In Search of Citizen Perspectives on the Smart City ${ }^{\dagger}$
}

\author{
Vanessa Thomas ${ }^{1, *, \ddagger}$, Ding Wang ${ }^{1, \ddagger}$, Louise Mullagh $^{1, \ddagger}$ and Nick Dunn ${ }^{2}$ \\ 1 HighWire Centre for Doctoral Training, Lancaster University, Bailrigg LA1 4YW, UK; \\ d.wang4@lancaster.ac.uk (D.W.); 1.mullagh@lancaster.ac.uk (L.M.) \\ 2 ImaginationLancaster, LICA/Lancaster University, Bailrigg LA1 4YW, UK; nick.dunn@lancaster.ac.uk (N.D.) \\ * Correspondence: v.thomas1@lancaster.ac.uk; Tel.: +44-1524-510311 \\ $+\quad$ This paper is an extended version of our paper published in the 8th Conference of the International \\ Forum on Urbanism. \\ $\ddagger$ These authors contributed equally to this work.
}

Academic Editor: Thorsten Schuetze

Received: 30 November 2015; Accepted: 13 February 2016; Published: 26 February 2016

\begin{abstract}
This paper builds upon an earlier conference publication by the authors, offering contributions based on a systematic literature review and qualitative study. The paper begins by drawing attention to the paucity of "citizen"-more appropriately, "situated" - perspectives on what a smart city should and could be. The paper then addresses that absence by detailing a research project that explored how people in London, Manchester, and Glasgow responded to the smart city concept. Participants were asked questions regarding their prior familiarity with the phrase "smart city", their thoughts relating to what it means for a city to be smart, and what a "true" smart city might mean to them. The paper analyses and offers a synthesis of the responses collected throughout the research with the dominant rhetoric about smart cities, as identified through a recent systematic literature review, thereby providing a critical assessment of the values underlying the smart city. It aims to explore and present some of the expectations that citizens hold for their cities' politicians, policy makers, planners, academics, and technology companies. We believe that these perspectives from citizens can be used to inform responsible development, spatially and socially inclusive technologies, and ultimately more resilient cities.
\end{abstract}

Keywords: smart cities; participation; community-based development; local knowledge

\section{Introduction}

This paper builds upon a previous conference publication [1] and describes a research project carried out in 2015. The project explored people's familiarity with and impressions of the smart city concept in three of the United Kingdom's smart cities: London, Manchester and Glasgow. Initial findings suggested that most participants were unaware of what a smart city is, but many were willing to use their familiarity with the term smartphone to guess what a smart city might be [1]. The project also explored citizens' visions for future smart cities, during which four clear themes emerged: the role of digital technologies in future smart cities, the importance of privacy, the value of community, and the desirability of interconnected and multi-modal transportation services.

Large scale visions of the smart city that are presented in many academic research papers and corporate marketing materials seem in direct contrast to the ways in which citizens envision it [1]. The citizen's vision and sense of scale is a perspective that is largely absent from the literature surveyed for this research project [1]. In this respect, our paper seeks to introduce the concept of smaller, 
more tangible interventions in the city that have the potential to be more meaningful for citizens. Rhetoric surrounding smart cities falls broadly into two categories: marketing material from large IT companies such as Hitachi [2] and IBM [3,4], and academic literature relating to technological interventions in the urban environment $[5,6]$. Smart city literature is being published at a fast pace, but as yet there has been very little produced in the way of critical discourse in this area [3]. The proliferation of smart city literature results partly from the increase in city populations, with the majority of the world's population living in urban areas for the first time in history [7]. This expanding area of academic study and marketing literature deals with a wide variety of technologies in an urban context.

There is no complete definition of what a "smart city" is, but common themes and terms run through them. In "Smart cities in Europe", Caragliu states "a city can be called a "smart" city when investments and human and social capital and traditional ICT infrastructure fuel a sustainable economic growth and a high quality of life, with wise management of natural resources" [8]. At the heart of this definition is the consideration of humans, but only insofar as they might be harnessed to enable growth. The smart city discourse tends to present the view that only through the deployment of technologies will the quality of life improve, which may certainly be the case for some, but not for all, within the city. Views and experiences of those who actually live in cities and will be affected by this move towards the autonomous urban realm are largely ignored within the literature. Even where literature calls for their involvement, none is forthcoming [9]. Caragliu's definition can be contrasted with the following statement, taken from a white paper on "Smart cities and the internet of everything" (2013), which states "smart cities are a future reality for municipalities around the world. These cities will use the power of ubiquitous communication networks, highly distributed wireless sensor technology, and intelligent management systems to solve current and future challenges and create new services" [10]. Both definitions place technologies at the heart of the smart city, with the presumption that through the deployment of "smart" initiatives, the city will expand and its problems will be ameliorated through technology alone.

Descriptions of smart city visions are predominantly large and deal with infrastructure, such as control centres, which have the ability to monitor areas such as traffic or crime using live data and to implement immediate measures to rectify situations [4,11]. This is already happening in cities across the world and is manifest in various systems, such as the use of "smart transport cards" like London's Oyster Card, smart grid sensor network systems [12], and domestic energy usage interventions [13,14]. Moreover, many people living in the city already use existing ICT solutions, such as location-based mobile phone applications, so what the label "smart city" is adding in terms of value is unclear, particularly to those living in smart cities such as London, Glasgow and Manchester.

A more critical discourse that challenges assumptions relating to the largely positive claims for the smart city is beginning to emerge. In the paper "Critical interventions into the corporate smart city", Hollands [15] suggests that such a reliance upon technologies as a panacea for a city's problems makes ideological assumptions that have not as yet been widely addressed. He asks "Who, and what, is driving our preoccupation with the smart city, and who stands to gain and lose in the race to such an urban future?" Questions relating to who gets left out and what people living in smart cities feel about this new environment are vital, but as yet are not being thoroughly addressed by academia or large IT companies [11,16-18]. This paper aims to address this absence of citizens and to add to the emerging critique of the smart city, based on evidence gathered during conversations with people living in and experiencing the phenomenon of the technological city.

We believe this research is one of the first of its kind, presenting the voices and perspectives of people approached in smart cities. The aims of this paper is threefold:

- Expand upon the systematic literature review and conference paper [1] to advance research relating to the inclusion of citizens' voices and perspectives in the smart city.

- Initiate a discussion regarding the importance of citizens' voices in the smart city research paradigm. 
- Add to the growing critique of the smart city [3] and question the as yet largely unquestioned approaches toward the impacts of technology in the city.

The paper is structured as follows: we begin by presenting the academic context for this paper, followed by an overview of the methods we used during the project, highlighting some of the challenges we encountered while applying these methods. This is followed by a discussion of our research results, as well as the implications of the results, and the limitations of the project. The paper is concluded by outlining questions that were left unanswered during the project.

\section{Research Context}

Our research began with a systematic literature review of research relating to citizen engagement and the smart city in three databases: the Association for Computing Machinery's (ACM) "Guide to Computing Literature", the Institute of Electrical and Electronics Engineers (IEEE) Xplore, and the International Academy, Research and Industry Association's (IARIA) ThinkMind. The preliminary search identified 474 papers that included the phrase "smart city" in their abstract. To narrow the focus of our re-view and answer our question, we selected several words and phrases, known as "filters" [19,20], used to describe human participation and involvement in urban and technical design projects. We filtered our results to include papers that used "citizen engagement", "participatory design", "co-design", and "consultation" somewhere in the body text. With these filters applied, we produced a set of thirty-five articles to review. However, three of the articles initially identified were duplicates and two were irrelevant because they were non-peer reviewed sources: one was a keynote speech and the other a one-page magazine article. Once we removed those five articles from our sample, we had thirty articles to review. The three primary authors of this paper conducted the review by reading through and coding ten randomly assigned articles, looking to identify type and forms of co-design, participatory design, and citizen engagement. Then the authors came together to cross-examine the coding, looking to address the research question: what involvement do people who live in smart cities have in smart city research?

The literature review found that people who live in smart cities are largely absent from, and uninvolved with smart city research. Of the thirty articles identified for review, only five articles directly and explicitly involved the residents of a smart city. In those five articles, one paper detailed a project that invited local residents to contribute to the definitional discourse about smart cities [21]. Three papers described projects that invited smart city residents to help with the development and design of smart city technologies [22-24]. The fifth paper described a project that "involved" smart city residents through participant observation, without any direct interaction or conversation with those being observed [5]. Five additional papers identified in the review [25-29] outlined projects that claimed to involve, or planned to involve, smart city residents. However, the details of the residents' involvement were excluded from the publication or were for a planned future phase of research. In the remaining twenty papers identified by our literature review, there was no clear evidence that people who live in smart cities were involved with the research. Ten papers [6,30-38] offered a variety of nuanced theoretical discussions about the smart city, at times even calling for increased citizen participation, but the wants, needs, perspectives, and actual involvement of smart city residents was absent from these papers. The remaining set of ten papers [39-48] presented smart city technologies that were being, or had been designed and developed, without the involvement of local residents. From the deployment of "smart dust" [39] to the development of "cloud-based big data analytics" [43], the involvement of local residents seemed to be an unnecessary issue for many smart city technology developers. As Khan, Anjum, and Kiani suggested, "at the core of smart cities is the collection, management, analysis and visualisation of huge amount of data that is generated every minute in an urban environment due to socioeconomic or other activities" [43]. Their view suggests that people are not at the core of the smart city; rather, people matter merely because of their ability to provide the data that drives the smart city. 
Based on the systemic literature review, we established that there is a dissonance between academic literature and practices of engagement within the city. Despite increased calls for citizen engagement, smart city residents appear to have been largely uninvolved with smart city research. When citizens have been involved with research, they have only been involved during the technology design process after technological solutions have already been conceptualised by academics and practitioners. Citizens have also only been engaged through the use of a limited set of methods including focus groups, interviews, and surveys. True co-design, which invites co-creation across the entire project lifecycle (e.g., participants are invited to design with scholars and practitioners from the outset of a project through to completion) [49], was entirely absent from the literature. The limited involvement of citizens, as identified in the review, carries serious implications for the future of the smart city. Numerous academics have already highlighted the necessity of involving citizens in urban development projects, from [50-52] to [53]. These insights point to a broader set of opportunities to undertake research that could enrich the smart city discussion and practice, and they are used to inform this research project.

\section{Fieldwork Methods}

We designed this project as an ethnographic exploration of people's familiarity with, impressions of, and experiences in "the smart city". We initially intended to approach people in three of the UK's "smart" cities, i.e., London, Manchester and Glasgow, and ask if they would be willing to participate in a semi-structured interview about their city. We also intended to keep observational journals that described how people responded to us, as well as how they were experiencing, living in, and interacting with their city and its "smart" features. Three ethnographers agreed to carry out this fieldwork over the course of three months in 2015. However, when we began conducting the fieldwork, we encountered two primary obstacles. First, we had difficulties recruiting participants on the street. Many people we approached claimed to be too busy or disinterested in the topic to participate. Several people did not meet the initial "citizen" criteria that we had set, which is a hurdle that will be discussed in greater detail in the "limitations" section of this paper. The second obstacle we encountered was with regards to our intent to make observations about people interacting with the "smart" city. Although a few "smart parks" and "smart" municipal service systems exist in the cities we studied, we found it difficult to observe people specifically interacting with those systems in and features of the city. As a result of these obstacles, we decided to cease our ethnographic observational endeavours and shift our attention instead towards collecting rich data from the few people who were willing to engage in conversations on the street.

In total, the fieldwork amounted to twenty-two semi-structured interviews [54], each of which lasted between seven and thirty one minutes in length. Our participants consisted of twenty men and two women, from a diverse age range (see Table 1); ten of our participants were from Glasgow, six were from London and six were from Manchester. Our participants had lived in their respective cities for varying lengths of time, ranging from less than one year to over thirty years (see Table 2). They were start-up founders, health-care support workers, web developers, managers, university students, office administrators, artist, and designers. During the interviews, we asked participants what they liked most about their city, if they were familiar with the term "smart city", what visions they had for a place called a "smart city", whether or not they believed they should be consulted during specific urban development projects, and what urban issues they believed were important. Three researchers transcribed the interviews, compiled field notes, and cross-examined the data for recurring themes, presented below for further discussion and exploration.

Table 1. Age of participants.

\begin{tabular}{cc}
\hline $\mathbf{3 0}$ and under & Over $\mathbf{3 0}$ \\
\hline 14 & 8 \\
\hline
\end{tabular}


Table 2. How long participants had lived in their city.

\begin{tabular}{ccc}
\hline Under $\mathbf{1}$ Year & $\mathbf{1 - 5}$ Years & 5+ Years \\
\hline 1 & 7 & 14 \\
\hline
\end{tabular}

\section{Results}

Our participants' responses are presented below, grouped according to their leading question (i.e., perspectives on the "smart city", visions for smart cities, and priorities for urban development) and the sub-themes that emerged from each question.

\subsection{Citizen Perspectives on the "Smart City"}

Just under half of our participants were familiar with the phrase "smart city" (see Table 3). Ten said that they had heard the phrase before; three mentioned that they had encountered it at work. Although two participants hesitated to offer their own definition of the concept, the others provided different explanations of what they thought a smart city might be. One suggested that the smart city was "about interconnected services and devices, [such as] smart meters in homes and hot-spots and bus trackers", while another stated that a smart city "is a city that can react day-to-day to its population". One participant confessed, "I think it's quite unclear what it actually means and I think it means different things to different people". None of the participants who claimed they were familiar with the term mentioned any specific companies, universities or academics involved with smart city development.

Table 3. People who were familiar with the phrase smart city.

\begin{tabular}{cc}
\hline Yes & No \\
\hline 10 & 12 \\
\hline
\end{tabular}

Of the twelve participants who were unfamiliar with the phrase, seven offered to guess what a smart city might be. The detail they offered varied widely. One participant in Glasgow said that a smart city "would be a city in which everything is smart, like smart phones and smart cameras and everything like that". A participant in Manchester said that a smart city would exist if "city planners used data to make areas improved". Another participant explained that the phrase smart city "brings up images of everything being connected in a digital sort of way", but she reiterated that she was only guessing. Yet again, none of the participants named specific companies, universities or academics. Moreover, none of our participants used the words efficiency, effectiveness or competitiveness, which appear to be very popular in smart city literature and marketing materials. Many of our participants struggled to be more specific than referencing existing technologies that use the label "smart", suggesting that the phrase was not very relatable for most people. Despite this lack of relatabilty, every participant was willing to respond to our visioning question and describe what features they might want to see in a smart city.

\subsection{Visions for Smart Cities}

When asked to describe what he or she would like to see from a future smart city, every participant offered a unique vision. Much like the definitions above, these visions varied significantly in terms of content and depth. Despite the variety amongst visions, four interconnected themes emerged during the interviews: the role of digital technologies in future smart cities, the value of community, the desirability of interconnected and multimodal transportation services, and the importance of privacy.

On the role of digital technologies in future "smart cities", some participants thought that technology would be a key driver of future developments, whereas others resisted the idea that 
our lives could be more reliant on technology. For example, one London-based participant described a technology-driven city that would be "kind of like in Silicon Valley, where technology is very ingrained and in tune with the city. People would interact as they do today in normal, daily life, but what would end up happening is that the technology would be so integrated that it [would] become part of a seamless experience." He went on to describe a shopping experience with digitally augmented windows that recommended nearby products and experiences based on the previous history of the shopper; this would allow every shopper to see an individualised set of advertisements, and have a personal shopping experience, which the participant felt would be very valuable. One Glaswegian participant had a different vision for bringing value to a smart city's inhabitants, explaining that he "would like to see Glasgow use technology to help with the health issues that the city suffers from. Obviously it's got a really low life expectancy in certain areas and fitness is quite a bad problem in Glasgow, so if you were able to use technology to help people [address] that on a daily basis, then that would be something that would really improve the overall feeling of the city". Several other participants described digitally augmented buildings that would respond to air pollution levels, maps that advised people on how to avoid pollution on their commutes, and networked trash bins that would automatically transmit their the waste management authority. However, these technology-centric visions were not popular with all of our participants. One London-based participant acknowledged that his envisioned smart city would likely "mediate conversations through technology, but [he] wouldn't be happy with that. [He] would want more sincerity, community, and good old fashioned talking". This was echoed by another participant who admitted that his future smart city would likely feature a lot of advanced technologies, but that he would not necessarily be happy with that. He wanted more community connections, less isolation, and more infrastructures that encouraged sustainable lifestyles, but he was not convinced that technology could deliver any of those. These latter visions were more people-centric than technology-centric, and they underscored another sub-theme that emerged in our interviews: many people believed that community should be a primary driver of the smart city.

Having a sense of "belonging" mattered to most of our participants. In nearly every interview, our participants eventually stated that having a sense of community in their city-through their connections with friends, families and acquaintances-mattered the most to them. Several participants described apps that could facilitate connections amongst neighbours, raise awareness about community events, and notify people about social opportunities. As one participant plainly stated, "if technology could be used to facilitate community interaction, then that would be great". Our participants not only expressed an interest in wanting to feel like they belonged within their immediate geographical and social communities; they also wanted to belong within their city's urban development community. In their imagined smart cities, most participants wanted to be consulted about, or at the very least made aware of, technological and infrastructural changes that would take place. They wanted to know what would be happening, where it would be happening, when it would be happening, and what that would mean for them. One participant asserted that "the installation of any sort of tool for technological surveillance should be made public". Another echoed this sentiment, and noted that even the installation of something like a smart meter could cause community unrest if it were not installed with plenty of notice, "because that's not just infrastructure change, that's social change, as well". Thus, in our participants' imagined smart cities, communication and connectivity between people, projects and places mattered. That connectivity was expressed in social terms, as well as spatial terms.

Transportation services and infrastructure were mentioned by almost all of our participants. In nearly every envisioned smart city, people described having access to reliable, real-time transportation information. In several visions, this information included direct updates about the arrival times of public transportation services, easily accessible maps of city-wide traffic flows, automated notifications about construction projects, and web-based maps of bicycle routes. One London-based participant praised Transport for London's services, noting that he thought 
"London is really good because there is a lot of information about the transit system". But not all participants felt the same way. One Glaswegian participant explained that "one of the things [he] tends to think about mostly is public transport and having access to up-to-the-minute public transport information. Being able to do that very easily from wherever [he is] around the city, and that taking into account [...] other information about what's going on in the city that day" was still an envisioned, future smart city offering for him. Moreover, some participants went further than just describing the delivery of information about transportation routes and services. Some described a full-scale reimagining of transportation infrastructure. For example, one participant explained that he wanted to see "tube systems that were connected to other systems and they would operate in a synchronous format." The same participant went on to explain that "in a lot of cities, they are chunking off a part of the road and dedicating it as a cycle lane. I think that an entirely separate route for cycling would make me cycle more [and I would like that]". Another participant mentioned wanting to see "a network of automated vehicles [that] is integrated with infrastructures". These latter types of envisioned smart city experiences cannot be achieved in most existing cities without making some change to physical, as well as digital, infrastructure. But for some of our participants, those physical and digital infrastructural changes were accompanied by concerns about some very real risks.

Many of our participants expressed concerns about who would own the technologies, data, and decision-making processes within their imagined "smart city". Once again, there was considerable variation amongst participants' opinions on the importance of these issues. Some participants felt that they should be advised about any and all data sharing processes, whereas others believed that regular consultation and awareness-raising processes would significantly inhibit urban development projects. Others held highly nuanced perspectives about the use, context and ownership of data, explaining that they would need to know the specific details of a digitally driven project before being comfortable with its installation in their neighbourhood. Some participants were especially concerned about partnerships with private companies because those companies may wish to make a profit off of public information, data and services. As one participant explained, "a lot of the time, technology is applied in an urban area by a corporate organisation, and it tends to be about making something more efficient with the end purpose of making more money or making something more profitable. If [my data] is just contributing to a product, then that's not something that I would be happy [about]." However, we encountered two other participants who explicitly stated that they were not concerned about whether a private company would use their data as long as there was some personal benefit from that company's product.

\subsection{Priorities for Urban Development}

In our closing discussion, we asked participants about the "urban issues" they believed were most important to address in cities. Although we asked them to respond "yes" or "no" to a list of eleven priorities (i.e., the water supply; climate change and air pollution; traffic; urban waste management; urban sprawl; threats to wildlife; green energy sources; public health issues; inequality and poverty; crime, and; transparent government), many participants offered additional descriptions of why they felt certain issues needed to be addressed. As a result, although we initially intended to ignore the responses to this question and simply use it as an outro for the interviews, our participants' responses offered additional insights into their visions for smart cities. For example, although almost no one had specifically described a smart city that reduced inequality and addressed poverty, eighteen of our twenty-two participants stated that they believed poverty and inequality were urban issues that needed to be addressed urgently. As one participant explained, "if we are reaching out to more people by becoming a smart city, then more people could see that [homelessness and inequality] exist and this is a problem that needs to be addressed". Conversely, despite the fact that nearly every participant mentioned the importance of transportation information and infrastructure, only twelve of twenty-two participants felt that traffic specifically was an important urban issue that needed to be addressed. 


\section{Discussion}

The perspectives expressed throughout our interviews were nuanced and at times contradictory. Respondents simultaneously envisioned a technologically enabled city that used their data for personalised services, yet demanded that those services respected their privacy and enhanced their sense of community. Such multi-faceted views reinforce the notion that cities and their inhabitants negotiate a vastly complex reality that likely cannot be simplified to one experience, let alone one vision of a "smart" city. However, the large-scale visions for smart cities expressed in academic papers, marketing materials, and government publications $[3,16,17,21,53]$ tend to simplify this context by placing technologies at the heart of the smart city, with a particular emphasis on efficiency over other outcomes. By promoting a city that is knowable and controllable in every aspect, the smart city paradigm offers holistic management and response strategies, some of them novel. However, this simplification does not align with how people imagined their future smart city. As such, we believe that there is not, and perhaps cannot be, a singular "true" smart city. This is perhaps no surprise given that cities are spatial, heterogeneous and typically developed over extensive periods of time. Indeed, AlAwadhi and Scholl [21] stated that "it might be pointless to strive for an exact and coherent academic definition of either 'Smart City' (local government) or 'smart city' (multidimensional urban space). Rather either term might be more helpful when understood as marking a conversation among stakeholders in local government and in the respective urban spaces about where the city and its government are actually going, and where they might need to go (instead)." While we agree that it might be most useful to simply accept that the term "smart city" might be useful for marking some conversations with some stakeholders (e.g., academics and local government employees), our interviewees' bewilderment at the term suggests that the phrase is not very helpful, efficient or effective for engaging in conversations with people who live in "smart" cities. Our participants found the phrase to be distant, unrelatable and abstract. This remoteness raises a crucial issue with regard to empathy, which is central to social capital and not readily amenable within technologies, especially the smart city, that predicate efficiency and large-scale mediated transactions over face-to-face interactions. It also reminds us that much of the "smartness" in these locations is a result of unseen technological infrastructures and objects: whether buried, place on rooftops or digital, they remain undetectable by the majority of people in a city.

We also found that many grand-scale smart city visions were not evident in and did not integrate well with the cities that we researched. Even our interviewees agreed. As one of the participants pointed out, the smart city is a good idea in theory, but not for a well-established city like London. At this point in time, the smart city vision appears to be a technologically driven rather than citizen-centric utopian vision that is being used to address complex urban problems. However, for decades, urbanists worldwide have been arguing the significance of citizens' involvement whenever we attempt to address complex urban problems [50-53]. As [51] states, "the freedom to make and remake our cities and ourselves is [...] one of the most precious yet most neglected of our human rights." What motivates us most to propose the people's perspective of smart cities is our strong belief that people have rights to their city. The right to the city, as Harvey [51] then argued, is far more than the individual liberty to access urban resources: it is a right to transform individuals by changing the city. As it is a common rather than an individual right, this transformation has to be based upon the collective exercising power in the processes of urbanisation [51]. In addition, by understanding citizen perspectives, needs and desires, there is a the potential to implement local interventions that may be advantageous for the wider scale of the city but not identifiable from a large-scale holistic strategy. Although our research was not designed to enable citizen participation in the processes of urbanisation, it was designed to bring a new dimension (citizen perspectives) to the smart city discourse. Thus, we believe that by presenting the nuanced, at times conflicting perspectives of citizens, our research can be used to inform the responsible development of spatially and socially inclusive technologies. 


\section{Reflections on This Research}

Although we believe this research project achieved its initial aims, we think it is important to reflect on the work and acknowledge some of its limitations. For example, as noted in the methods section, we were unable to recruit the number of participants that we had hoped to recruit. This in itself appears reflective of the disjunction between the concept and the everyday experience of citizens. We interviewed a very small portion of the inhabitants of London, Manchester and Glasgow, and our participants' demographics hardly represent the true diversity of those cities. Moreover, our data gathering took place entirely within the United Kingdom, meaning that many of our participants' responses were based within a society that has an existing social welfare system. We believe that smart city based interviews in other countries, such as the United States, Denmark, and Colombia, would likely attract very different responses. As such, the quantity, lack of diversity, and geographic scope of our research could be seen as limitation to this project.

Similarly, although this research was inspired by a broad set of multidisciplinary readings, its narrowly scoped literature review could be seen as a limitation. Future work could allocate more space for discussion with other communities that operate in the smart city field. For instance, reviewing works in human geography or human-computer interaction's (HCI) sub-fields of urban computing, urban interaction design (urban IxD) [54], urban informatics [55], and media architecture might offer interesting perspectives to the discourse. Within those fields, some literature addresses citizen participation by focusing on questions around the "smart city" vs. the "smart citizen" [56], top-down vs. bottom-up approaches [57,58], and new forms of policy and governance vs. unique expressions of do-it-yourself (DIY) urbanism globally [59]. These debates have not been touched on in this paper, but they provide fertile fodder for civic engagement; we expect to include them in future work, especially if we wish to make a strong case for "how" to deliver projects and meet demands.

Lastly and most importantly, though, we believe that we must reflect on our initial use of the term "citizen", as it was a clear limitation to our work. A citizen is "a legally recognized subject or national of a state or commonwealth, either native or naturalized" [60]. Within the urban design sphere, use of the term "citizen" does not include all of the people living in, residing in or making use of spaces within cities. In our project specifically, we battled with the limitations of the term "citizen" throughout our participant recruitment. Many of the people we approached during our first recruitment drive on the streets of London were, in fact, tourists. These tourists-who represent a group that spends a significant amount of money within England annually and makes use of many smart city applications and services [61] — had to be excluded from the initial scope of our research because not a single one of them technically counted as a citizen of the United Kingdom. After being careful about our terminology and turning away dozens of tourists, we still unintentionally interviewed two non-citizens. Two of our participants were residents in the United Kingdom, but they were here on working visas that had been issued for between one and five years of residency. A temporary resident, despite paying taxes and integrating into the local community, is not a citizen, and we therefore found ourselves in yet another conundrum. Although our research team initially chose to use the term citizen for this research project because it appeared throughout many smart city research papers, we no longer believe it is an appropriate term to use when discussing the people who should be served by a "smart city". A simple substitution of the term "citizen" with the term "user" or "resident" or "local" is no better, because each of those terms carries its own unacceptable baggage. For any researchers looking to avoid this limitation in the future, we would instead recommend the adoption of a simpler, broader term: "people".

\section{Conclusions}

The object of this paper was to build upon the data presented in our previous conference publication. The project found that most interviewees were unfamiliar with what a smart city is, and they found the phrase to be distant, obscure and abstract. When asked to discuss their visions for future smart cities, citizens were concerned with the role digital technologies might 
play in future smart cities, privacy, the interconnectedness of multimodal transportation services, and community. By presenting the nuanced and at times conflicting perspectives and demands of citizens, we believe our research can be used to inform responsible development, spatially and socially inclusive technologies, and ultimately more resilient cities.

We also believe that our project has highlighted many opportunities for future research endeavours. For example, since our project was situated in smart cities within the UK, we suspect that it would be of value to undertake similar projects in other contexts. Research in greenfield smart cities, such as Masdar City and New Songdo, could provide additional and useful insights into local expectations. Moreover, since our project shifted its focus to rely on interviews with citizens, we think there are opportunities to use other means for involving citizens in smart city research and development, such as ethnography and surveys. We therefore call upon smart city researchers to come together in order to develop, extend, and enrich the involvement of citizens in the rhetoric and implementation of smart city work.

Supplementary Materials: All data created during this research are openly available from Lancaster University data archive at http://dx.doi.org/10.17635/lancaster/researchdata/61 [54].

Acknowledgments: This work is partially funded by the Digital Economy programme (RCUK Grant EP/G037582/1), which supports the HighWire Centre for Doctoral Training (highwire. lancs.ac.uk).

Author Contributions: Ding Wang, Louise Mullagh and Vanessa Thomas contributed equally to this project by planning and conducting the literature review, fieldwork, analysis and paper drafting. Professor Nick Dunn provided crucial and significant oversight and guidance throughout this project, prompting us to refine and revise our methods, analysis and framing.

Conflicts of Interest: The authors declare no conflict of interest.

\section{References}

1. Thomas, V.; Mullagh, L.; Wang, D.; Dunn, N. Where's Wally? In Search of Citizen Perspectives on the Smart City. In Proceedings of the 8th Conference of the International Forum on Urbanism (IFoU), Incheon, South Korea, 22-24 June 2015; pp. 1-8.

2. HITACHI'S, S.C.T. Hitachi's Vision of the Smart City. Hitachi Rev. 2012, 61, 111.

3. Galdon-Clavell, G. (Not so) smart cities?: The drivers, impact and risks of surveillance-enabled smart environments. Sci. Public Policy 2013, 40, 717-723.

4. IBM Corporation. Smarter, More Competitive Cities. Available online: http://smartcitiescouncil.com/ system/tdf/public_resources/Smarter,\%20more\%20competitive\%20cities.pdf?file=1\&type=node\&id=156 (accessed on 19 February 2016).

5. Wang, S.-M.; Huang, C.-J. User experience analysis on urban interaction and information service in smart city nodes. In Proceedings of the Second International Symposium of Chinese CHI, Chinese CHI '14, Toronto, ON, Canada, 26-27 April 2014; ACM: New York, NY, USA, 2014; pp. 103-109.

6. Anthopoulos, L.; Fitsilis, P. Considering Future Internet on the Basis of Smart Urban Cities A Client-City Architecture for Viable Smart Cities. In Proceedings of the Fourth International Conference on Evolving Internet (INTERNET 2012), Venice, Italy, 24-29 June 2012.

7. Shelton, T.; Zook, M.; Wiig, A. The 'actually existing smart city'. Camb. J. Reg. Econ. Soc. 2014. [CrossRef]

8. Caragliu, A.; Del Bo, C.; Nijkamp, P. Smart Cities in Europe. J. Urban Technol. 2011, 18, 65-82. [CrossRef]

9. Kitchin, R. Opening up smart cities: A report on the Smart City Expo World Congress. Available online: http:/ /www.maynoothuniversity.ie/progcity/2014/11/opening-up-smart-cities-a-report-on-the-smart-city -expo-world-congress / (accessed on 19 February 2016).

10. Yesner Clarke, R. Smart Cities and the Internet of Everything: The Foundation for Delivering Next-Generation Citizen Services; Technical Report; Cisco; IDC Government Insights: Alexandria, VA, USA, 2013.

11. Kitchin, R. The Real Time City; National University of Ireland: Maynooth, Ireland, 2013; pp. 1-20.

12. Leccese, F.; Cagnetti, M.; Trinca, D. A Smart City Application: A Fully Controlled Street Lighting Isle Based on Raspberry-Pi Card, a ZigBee Sensor Network and WiMAX. Sensors 2014, 14, 24408-24424. [CrossRef] [PubMed] 
13. Leccese, F. A first analysis of Perceived Power Quality for domestic customers. In Proceedings of the 12th IMEKO TC1 \& TC7 Joint Symposium on Man Science \& Measurement September, Annecy, France, 3-5 September 2008; pp. 3-5.

14. Clear, A.K.; Morley, J.; Hazas, M.; Friday, A.; Bates, O. Understanding Adaptive Thermal Comfort: New Directions for UbiComp. In Proceedings of the 2013 ACM International Joint Conference on Pervasive and Ubiquitous Computing (UbiComp'13), Zurich, Switzerland, 8-12 September 2013; ACM: New York, NY, USA, 2013; pp. 113-122.

15. Hollands, R.G. Critical interventions into the corporate smart city. Camb. J. Reg. Econ. Soc. 2014. [CrossRef]

16. Hollands, R.G. Will the real smart city please stand up? City 2008, 12, 303-320. [CrossRef]

17. Greenfield, A. Against the Smart City: The City is Here for You to Use, 1.3 ed.; Do Projects: New York, NY, USA, 2013.

18. Nam, T.; Pardo, T.A. Conceptualizing smart city with dimensions of technology, people, and institutions. In Proceedings of the 12th Annual International Digital Government Research Conference: Digital Government Innovation in Challenging Times, College Park, MD, USA, 12-15 June 2011; pp. 282-291.

19. Tranfield, D.R.; Denyer, D.; Smart, P. Towards a methodology for developing evidence-informed management knowledge by means of systematic review. Br. J. Manag. 2003, 14, 207-222. [CrossRef]

20. Kitchenham, B. Procedures for performing systematic reviews. Keele University: Keele, UK, 2004; Volume 33, pp. 1-26.

21. AlAwadhi, S.; Scholl, H.J. Aspirations and realizations: The smart city of Seattle. In Proceedings of the 2013 46th Hawaii International Conference on System Sciences (HICSS), Wailea, Maui, HI, USA, 7-10 January 2013; pp. 1695-1703.

22. Veeckman, C.; van der Graaf, S. The city as living labortory: A playground for the innovative development of smart city applications. In Proceedings of the 2014 International ICE Conference on Engineering, Technology and Innovation (ICE), Bergamo, Italy, 23-25 June 2014; pp. 1-10.

23. Di Fiore, A.; Chinkou, J.; Fiore, F.; D'Andrea, V. The need of e-learning: Outcomes of a partecipatory process. In Proceedings of the 2013 Second International Conference on e-Learning and e-Technologies in Education (ICEEE), Lodz, Poland, 23-25 September 2013; pp. 318-322.

24. Vicini, s.; Bellini, S.; Sanna, A. Co-production of health in smart cities: The $\mathrm{m} 3$ case study. In Proceedings of the Second International Conference on Smart Systems, Devices and Technologies (SMART 2013), Rome, Italy, 23-28 June 2013; pp. 71-75.

25. Schaffers, H.; Komninos, N.; Pallot, M.; Trousse, B.; Nilsson, M.; Oliveira, A. Smart cities and the future internet: Towards cooperation frameworks for open innovation. In The Future Internet, vol. 6656 of Lecture Notes in Computer Science; Springer: Berlin, Germany; Heidelberg, Germany, 2011; pp. 431-446.

26. Gaved, M.; Jones, A.; Kukulska-Hulme, A.; Scanlon, E. A Citizen-Centred Approach to Education in the Smart City. Int. J. Digital Lit. Digital Competence 2012, 3, 50-64. [CrossRef]

27. Komninos, N.; Tsarchopoulos, P.; Kakderi, C. New services design for smart cities: A planning roadmap for user-driven innovation. In Proceedings of the 2014 ACM International Workshop on Wireless and Mobile Technologies for Smart Cities, WiMobCity '14, Philadelphia, PA, USA, 11-14 August 2014; ACM: New York, NY, USA, 2014; pp. 29-38.

28. Nam, T.; Aldama, F.A.; Chourabi, H.; Mellouli, S.; Pardo, T.A.; Gil-Garcia, J.R.; Scholl, H.J.; Ojo, A.; Estevez, E.; Zheng, L. Smart cities and service integration. In Proceedings of the 12th Annual International Digital Government Research Conference: Digital Government Innovation in Challenging Times, dg.o '11, College Park, Maryland, USA, 12-15 June 2011; ACM: New York, NY, USA, 2011; pp. 333-334.

29. Aldama-Nalda, A.; Chourabi, H.; Pardo, T.A.; Gil-Garcia, J.R.; Mellouli, S.; Scholl, H.J.; Alawadhi, S.; Nam, T.; Walker, S. Smart cities and service integration initiatives in north american cities: A status report. In Proceedings of the 13th Annual International Conference on Digital Government Research, dg.o '12, College Park, MD, USA, 4-7 June 2012; ACM: New York, NY, USA, 2012; pp. 289-290.

30. Cohen, S.; Money, W.; Quick, M. Improving Integration and Insight in Smart Cities with Policy and Trust. In Proceedings of the 4th International Conference on Web Intelligence, Mining and Semantics (WIMS14), Thessaloniki, Greece, 2-4 June 2014; ACM Press: New York, New York, USA, 2014; pp. 1-9.

31. Anthopoulos, L.; Vakali, A. Urban planning and smart cities: Interrelations and reciprocities. In The Future Internet, F. Alvarez, Ed., vol. 7281 of Lecture Notes in Computer Science; Springer: Berlin, Germany; Heidelberg, Germany, 2012; pp. 178-189. 
32. Anttiroiko, A.-V.; Valkama, P.; Bailey, S. Smart cities in the new service economy: Building platforms for smart services. AI Soc. 2014, 29, 323-334. [CrossRef]

33. Cosgrave, E.; Tryfonas, T. Exploring the relationship between smart city policy and implementation. In Proceedings of the First International Conference on Smart Systems, Devices and Technologies (SMART 2012), Stuttgart, Germany, 27 May-1 June 2012; pp. 79-82.

34. Daniel, S.; Doran, M.-A. Geosmartcity: Geomatics contribution to the smart city. In Proceedings of the 14th Annual International Conference on Digital Government Research, dg.o '13, Quebec City, Canada, 17-20 June 2013; ACM: New York, NY, USA, 2013; pp. 65-71.

35. Jollivet, P. Crowdsourced security, trust \& cooperation for learning digital megacities: Valuing social intangible assets for competitive advantage and harmonious development. In Proceedings of the IET International Conference on Smart and Sustainable City (ICSSC 2011), Shanghai, China, 6-8 July 2011; pp. 1-4.

36. Datumaya Wahyudi Sumari, A. Smart military society: Defining the characteristics to score the "smart" of the military services. In Proceedings of the 2013 International Conference on ICT for Smart Society (ICISS), Jakarta, Indonesia, 13-14 June 2013; pp. 1-8.

37. Nam, T.; Pardo, T.A. Conceptualizing smart city with dimensions of technology, people, and institutions. In Proceedings of the 12th Annual International Digital Government Research Conference: Digital Government Innovation in Challenging Times, dg.o '11, College Park, Maryland, USA, 12-15 June 2011; ACM: New York, NY, USA, 2011; pp. 282-291.

38. Mullagh, L.; Blair, L.; Dunn, N. Beyond the 'smart' city: Reflecting human values in the urban environment. In Proceedings of the Third International Conference on Smart Systems, Devices and Technologies (SMART 2014), Paris, France, 20-24 July 2014; pp. 43-46.

39. Edwards, C. Smart dust. Eng. Technol. 2012, 7, 74-77. [CrossRef]

40. Nam, T.; Pardo, T.A. Smart city as urban innovation: Focusing on management, policy, and context. In Proceedings of the 5th International Conference on Theory and Practice of Electronic Governance, ICEGOV '11, Tallinn, Estonia, 26-28 September 2011; ACM: New York, NY, USA, 2011; pp. 185-194.

41. Nam, T.; Pardo, T.A. Transforming city government: A case study of philly311. In Proceedings of the 6th International Conference on Theory and Practice of Electronic Governance (ICEGOV '12), Albany, NY, USA, 22-25 October 2012; ACM: New York, NY, USA, 2012; pp. 310-319.

42. Lea, R.; Blackstock, M. Smart cities: An iot-centric approach. In Proceedings of the 2014 International Workshop on Web Intelligence and Smart Sensing, IWWISS '14, Saint Etienne, France, 1-2 September 2014; ACM: New York, NY, USA, 2014; pp. 12:1-12:2.

43. Khan, Z.; Anjum, A.; Kiani, S. Cloud based big data analytics for smart future cities. In Proceedings of the 2013 IEEE/ACM 6th International Conference on Utility and Cloud Computing (UCC), Dresden, Germany, 9-12 December 2013; pp. 381-386.

44. Hu, X.; Li, X.; Ngai, E.-H.; Leung, V.; Kruchten, P. Multidimensional context-aware social network architecture for mobile crowdsensing. IEEE Commun. Mag. 2014, 52, 78-87. [CrossRef]

45. French, T.; Bessis, N. Towards a Context-Aware and Adaptable Room System for Intelligent "Trusted" Office-Spaces in Smart Cities. In Proceedings of the 2012 Sixth International Conference on Innovative Mobile and Internet Services in Ubiquitous Computing (IMIS), Palermo, Italy, 4-6 July 2012; pp. 148-154.

46. Ferreira, J.; Afonso, J. Mobi system: A personal travel assistance for electrical vehicles in smart cities. In Proceedings of the 2011 IEEE International Symposium on Industrial Electronics (ISIE), Gdansk, Poland, 27-30 June 2011; pp. 1653-1658.

47. David, B.; Yin, C.; Zhou, Y.; Xu, T.; Zhang, B.; Jin, H.; Chalon, R. Smart-city: Problematics, techniques and case studies. In Proceedings of the 2012 8th International Conference on Computing Technology and Information Management (ICCM), 24-26 April 2012; Volume 1, pp. 168-174.

48. Silva, P.; Karnouskos, S.; Ilic, D. A survey towards understanding residential prosumers in smart grid neighbourhoods. In Proceedings of the 2012 3rd IEEE PES International Conference and Exhibition on Innovative Smart Grid Technologies (ISGT Europe), Berlin, Germany, 14-17 October 2012; pp. 1-8.

49. Sanders, E.B.N.; Stappers, P.J. Co-creation and the new landscape of design. CoDesign 2008, 4, 5-18. [CrossRef]

50. Lefebvre, H. The Production of Space; Oxford Blackwell: Oxford, UK, 1991.

51. Harvey, D. The New Imperialism; Oxford University Press: Oxford, UK, 2003. 
52. Jacobs, J. The Death and Life of Great American Cities; Random House: New York, NY, USA, 1961.

53. Soja, E. Regional urbanization and the end of the metropolis era. In New Companion to the City; Wiley-Blackwell: Chichester, UK, 2011; pp. 679-689.

54. Brynskov, M.; Carvajal Bermúdez, J.; Fernández, M.; Korsgaard, H.; Mulder, I.; Piskorek, K.; Rekow, L.; De Waal, M. Urban Interaction Design: Towards City Making; UrbanIxD Publications: Amsterdam, The Netherlands, 2014; Available online: http:/ /dx.doi.org/10.17635/lancaster/researchdata/61 (accessed on 24 February 2016).

55. Bilandzic, M.; Venable, J. Towards participatory action design research: Adapting action research and design science research methods for urban informatics. J. Community Inform. 2011, 7, 3.

56. Hemment, D.; Townsend, A. Smart Citizens; FutureEverything Publications: Manchester, UK, 2013 ; Volume 4.

57. Chelleri, L.; Kua, H.W.; Rodrigues, J.P.; Thondhlana, G.; Nahiduzzaman, N.K.; Abdullatif, A.S. Exploring the User-Driven Implications in Building Urban Sustainability and Resilience: Lessons from OURS CITIES Global Network Study Cases. In Proceedings of the 8th Conference of the International Forum on Urbanism (IFoU); Multidisciplinary Digital Publishing Institute: Incheon, Korea, 2015; pp. 58-69.

58. Calderon, C. Chelleri, LSocial processes in the production of public spaces: Structuring forces and actors in the renewal of a deprived neighbourhood in Barcelona. J. Urban Des. 2013, 18, 409-428. [CrossRef]

59. Anguelovski, I.; Chu, E.; Carmin, J. Variations in approaches to urban climate adaptation: Experiences and experimentation from the global South. Glob. Environ. Chang. 2014, 27, 156-167. [CrossRef]

60. Citizen. The Oxford English Dictionary; Oxford University Press: Oxford, UK, 2015.

61. Department for Culture, Media and Sport. Tourism Set for a Boost. Available online: https://www.gov.uk/ government/news/tourism-set-for-a-boost (accessed on 26 February 2016).

(C) 2016 by the authors; licensee MDPI, Basel, Switzerland. This article is an open access article distributed under the terms and conditions of the Creative Commons by Attribution (CC-BY) license (http:/ / creativecommons.org/licenses/by/4.0/). 